Verhaak, P.F.M., Dekker, J.H., Waal, M.W.M. de, Marwijk, H.W.J. van, Comijs, H.C. Depression, disability and somatic diseases among elderly. Journal of Affective Disorders: 2014, 167(oct.), 187-191

\begin{tabular}{|l|l|}
\hline $\begin{array}{l}\text { Postprint } \\
\text { Version }\end{array}$ & 1.0 \\
\hline Journal website & $\underline{\text { http://www.jad-journal.com/article/S0165-0327(14)00352-8/abstract }}$ \\
\hline Pubmed link & $\underline{\text { http://www.ncbi.nlm.nih.gov/pubmed/24992026 }}$ \\
\hline DOI & 10.1016/j.jad.2014.05.057 \\
\hline
\end{tabular}

This is a NIVEL certified Post Print, more info at http://www.nivel.eu

\title{
Depression, disability and somatic diseases among elderly
}

\author{
P.F.M. VERHAAK ${ }^{\text {A, B, , , J.H. DEKKER }}{ }^{A}$, M.W.M. DE WAAL ${ }^{\mathrm{C}}$, H.W.J. VAN MARWIJK ${ }^{\mathrm{D}}$, H.C. \\ COMIJS $^{\mathrm{E}}$ \\ ${ }^{a}$ Groningen University, University Medical Center Groningen, Department of General \\ Practice, Groningen, The Netherlands \\ ${ }^{\mathrm{b}}$ Netherlands Institute of Health Services Research, PO Box 1568, 3500 BN Utrecht, The \\ Netherlands \\ ${ }^{\mathrm{c}}$ Leiden University Medical Center, Department of Public Health and Primary Care, Leiden, \\ The Netherlands \\ ${ }^{\mathrm{d}}$ VU University Medical Center, Department of General Practice and EMGO Institute for \\ Health Care Research, The Netherlands \\ ${ }^{\mathrm{e}}$ VU University Medical Center/GGZinGeest, Department of Psychiatry and EMGO Institute \\ for Health Care Research, The Netherlands
}

\begin{abstract}
Objective

Depression among older adults is associated with both disability and somatic disease. We aimed to further understand this complicated relationship and to study the possible modifying effect of increasing age.

Design

Cross sectional survey.

Setting

Outpatient and inpatient clinics of regional facilities for mental health care and primary care.

Participants

Elderly people, 60 years and older, 378 persons meeting DSM-IV criteria for a depressive disorder and 132 non-depressed comparisons.

Measurements

Depression diagnoses were assessed with the CIDI version 2.1. Disability was assessed with the WHO Disability Assessment Schedule (WHODAS). Socialdemographic information and somatic diseases were assessed by self-report measurements.

Results
\end{abstract}


Verhaak, P.F.M., Dekker, J.H., Waal, M.W.M. de, Marwijk, H.W.J. van, Comijs, H.C. Depression, disability and somatic diseases among elderly. Journal of Affective Disorders: 2014, 167(oct.), 187-191

Disability, in general and on all its subscales, was strongly related to depression. Presence of somatic disease did not contribute independently to variance in depression. The relationship was stronger for people of 60-69 years old than for those older than 70 years. Important aspects of disability that contributed to depression were disability in participation, self-care and social activities.

Limitations

Results are based on cross sectional data. No inferences about causal relationships can be drawn.

Conclusion

Disability, especially disability regarding participation, self-care, or social activities is strongly related to late-life depression. Somatic diseases in itself are less of a risk for depression, except that somatic diseases are related to disability.

\section{INTRODUCTION}

Depression is a frequently occurring condition among older patients (Alexopoulos, 2005, Djernes, 2006, Licht-Strunk et al., 2009 and Unutzer, 2007). Late life depression may be different from depression among younger adults in several respects (Serby and Yu, 2003 and Serby and Yu, 2003). Important predictors for onset and persistence of late-life depression are female gender, low education, loss of partner, cognitive decline, somatic diseases, and functional impairment or disability (Djernes, 2006). Risk factors may cluster and the interaction of the latter two is particularly intriguing and often problematic in general practice.

The association between depression and disability is reported by many authors (Barry et al., 2009, Chen et al., 2012, Diefenbach et al., 2012, Garber et al., 2010, Pagan-Rodriguez and Perez, 2013, Penninx et al., 1998, Russo et al., 2007, Schillerstrom et al., 2008, Vink et al., 2008 and Yanagita et al., 2006). The same goes for depression and somatic disease, (Evans et al., 2005, Nuijen et al., 2006, Patten et al., 2005 and Vink et al., 2008).

Disability, somatic diseases and age all appear interrelated. Disability and somatic diseases become more frequent as people get older. It is unclear whether specific somatic disease and depression are related because of an etiological cause or whether somatic disease contributes to disability and disability causes depression (Schillerstrom et al., 2008). With growing age, relationships change as well: Mehta et al. (2008) concluded that among young-old (65-80) resilience, apathy and disability all equally contributed to the variance in depression score, whereas among the old-old ( $>80)$ apathy alone had the greatest contribution to depression. With an aging population, this entanglement of disability (both physical as psychosocial), somatic diseases, age and depression poses an important problem for focused health care delivery.

This brings forward the following research questions:

1.

Is somatic disease independently related to depression or is disability, associated with somatic disease, an explanatory factor?

2.

Are the relationships in question 1 moderated by age? 
Verhaak, P.F.M., Dekker, J.H., Waal, M.W.M. de, Marwijk, H.W.J. van, Comijs, H.C. Depression, disability and somatic diseases among elderly. Journal of Affective Disorders: 2014, 167(oct.), 187-191

\section{METHOD}

\subsection{Recruitment}

Data are derived from the baseline measurement of the Netherlands Study of Depression in Older persons (NESDO; http://nesdo.amstad.nl; Comijs et al., 2011). In this study respondents of 60 years and older have been recruited from mental health care and general practices in five different regions in the Netherlands. From the 378 depressed patients, 326 were included from outpatient and inpatient clinics for mental health care; 52 depressed patients were included from primary care. In addition, a comparison group of 132 non-depressed patients (not matched on any criterion) was included from primary care with a negative score on the GDS and no life-time diagnosis of depression. Inclusion criteria for the depressed group were a primary 6-month diagnosis of major depressive disorder, dysthymia or minor depression according to DSM-IV criteria (APA, 1994). Exclusion criteria for both groups were a primary clinical diagnosis of dementia, a Mini Mental State Examination-score (MMSE) below 18 (out of 30 points), and insufficient command of the Dutch language.

\subsection{Assessments}

Depression diagnoses were assessed with the Composite International Diagnostic Interview (CIDI; WHO version, 2.1; lifetime version.

Severity of depression was measured as a continuous measure with the Inventory of Depressive Symptoms (IDS; Rush et al., 1996) Disability was assessed with the WHO Disability Assessment Schedule ( Chwastiak and von Korff, 2003), with 6 subscales (see Table 4). Higher scores indicate more disability. The presence of somatic diseases was assessed by means of a self-report questionnaire, previously used in the Longitudinal Aging Study Amsterdam ( Kriegsman et al., 1996). Participants were asked whether they were under treatment of a medical doctor for a range of somatic diseases, including a category "other". The number of these somatic diseases, as far as patients were under treatment of a medical doctor, was used in the analyses. Socio-demographic characteristics. Of each participant, age, gender, educational level, partner status $(y / n)$, and household income was assessed.

\subsection{Analysis}

We first compared the group of depressed patients with the non-depressed comparison group by means of descriptive statistics. Variables that differed between groups $(p<0.10)$, were considered as possible confounders and included in the subsequent analyses. Secondly, we tested subsequent logistic regression models with depression diagnoses as outcome. In the first model somatic disease was included as the main determinant, controlling for possible socio-demographic confounders and age. In order to examine possible mediation by disability, in the second model this variable was added. Regarding possible differentiation between younger and older people we introduced in a third model the interaction term for age $\times$ disability and age $\times$ disease. For this purpose age is split up according to the median $(<70$ year,$\geq 70$ year). We tested the sum score of disability and the six sub-scales separately. All statistical analyses were carried out with Stata 13.0

\section{RESULTS}

Table 1 shows the characteristics of the depressed elderly and the non-depressed comparison group. Both groups had the same age and gender distribution. The 
Verhaak, P.F.M., Dekker, J.H., Waal, M.W.M. de, Marwijk, H.W.J. van, Comijs, H.C. Depression, disability and somatic diseases among elderly. Journal of Affective Disorders: 2014, 167(oct.) 187-191

depressed elderly were less often married and more often divorced, widowed or living apart from their partner. They were less well educated and their income was lower. In the multivariate analyses we will control for these possible confounders.

\section{[TABLE 1]}

The depressed elderly had more disability in all respects. On all disability subscales, depressed patients performed significantly worse. Depressed elderly did not differ from the comparison group with respect to the number of somatic diseases for which they were under treatment of a doctor nor with respect to the presence of any single somatic disease.

Table 2 presents the results of the logistic regression analysis. In the first step, the relationship between somatic disease and depression was tested. No significant effect of somatic disease was found. In model 2, after introduction of total disability score, a clear effect of disability $(\mathrm{OR}=1.22, p<0.001)$ together with an effect of somatic disease $(\mathrm{OR}=0.77, p=0.05)$ was demonstrated. Beta for somatic disease changed considerably from 0.03 in model 1 to -0.27 in model 2 .

\section{[TABLE 2]}

\section{[FIGURE 1]}

Because of the interaction effect, model 2 was repeated for 60-69 years old and 70+ separately. The results are shown in Table 3. In both age categories, only disability had a significant effect on depression, but the effect in the younger age group was slightly larger.

\section{[TABLE 3]}

Analyses as presented in Table 2, with the sum score on disability as one of the determinants, have been repeated with the six sub-scales of disability as determinants. The final models are presented in Table 4.

\section{[TABLE 4]}

Each of the six distinct aspects of disability was significantly related to depression, with disability in participation having the highest odds, followed by social activities and disability in self-care. Combined with disability in social activities, the lack of a partner increased the risk of depression. Interaction between age and the specific disability or between age and somatic disease did not contribute significantly to the odds for depression.

\section{DISCUSSION}

\subsection{Summary of results}

Somatic disease has no independent effect on depression. However, disability appears to be a suppressor of its negative effect: patients with somatic diseases have a lower risk to report depression when their level of disability is taken into account. In other words: disability increases the odds on depression among elderly. As somatic disease is correlated with disability, its negative relationship with depression is not visible unless we control for disability. These effects are more pronounced for 
Verhaak, P.F.M., Dekker, J.H., Waal, M.W.M. de, Marwijk, H.W.J. van, Comijs, H.C. Depression, disability and somatic diseases among elderly. Journal of Affective Disorders: 2014, 167(oct.), 187-191

patients between 60 and 70 years than for patients older than 70 years. Disability in persons above 60 years is the main factor, especially regarding participation, social activities and understanding/communication.

Of course, functional impairment is in itself a necessary condition for symptoms to be considered 'depressive' according to DSMIV. As such, depression already implicates disability (APA, 1994 p. 327). However, the concept as we measured it with the WHODAS is broader and the average scores of the depressed elderly are considerably higher than needed to fulfill DSM-IV criteria. Werff Evd et al. (2010) report comparable relationships between all subscales and depression in the relationship between the WHODAS disability subscales and depression in a population of adults aged 18-65 year. Although a number of studies report a relationship between depression and somatic diseases (see Section 1), few consider somatic disease together with disability or physical functioning. Turvey et al. (2009) concluded that somatic diseases predict depression, measured on a dimensional scale, better than depression measured categorically by CIDI. Somatic disease seems more a predictor for “an indicator for chronic illness burden”, as Myers and Weissman (1980) characterized the CES-D, according to Turvey et al. (2009), than for depression as a categorical disease.

Dunlop et al. (2004), exploring the effect of chronic illness and functional limitation, conclude that functional limitation mediates the association of arthritis and heart disease with major depression. These results, as well as those presented in this paper, suggest that impairment and disability, possibly consequences of somatic disease, are the principal associations with depression. As we combined all possible somatic diseases, this might have obscured the possible effect of single diseases. However, a repeated analysis with the most prevalent chronic diseases, heart disease, diabetes, arthritis and cancer, separately, resulted in comparable results as reported in Table 2, Table 3 and Table 4.

Our results also reflect the general finding that the presentation of depression is less specific among older patients. The relationship between depression and disability for $70+$ patients is less strong than for younger older patients. Among depressed patients, less disability is reported by older old depressed patients than by younger old depressed patients, whereas controls report more disability at an older age.

\subsection{Strengths and limitations}

We used a relatively large database with use of standardized instruments and thorough classification of mental disorder by the CIDI interview. Nevertheless, some limitations should be mentioned.

To start with the largest: Due to our cross sectional dataset, we cannot make any causal attributions.

Bruce (2001) points to three important methodological challenges. Selection bias can be at stake because both disability and depression may influence help seeking behavior and illness perceptions and the relationship between the two can be a result of the setting in which the relationship is observed. In our study the majority of depressed patients was included from another care setting (mental health institutions) than the non-depressed patients (primary care setting). The more specialized institutions, where the majority of depressed patients were found, might have attracted more severely disabled persons. However, we repeated our analysis for the depressed and non-depressed patients recruited in primary care only and found comparable results as reported for all respondents. Disability of depressed patients 
Verhaak, P.F.M., Dekker, J.H., Waal, M.W.M. de, Marwijk, H.W.J. van, Comijs, H.C. Depression, disability and somatic diseases among elderly. Journal of Affective Disorders: 2014, 167(oct.), 187-191

from primary care (26.0) was equal to that of non-general institutions (25.6) $t=0.23$; $p=0.41$. The major confounder in the observed relationship between disability and depression according to Bruce (2001) is medical illness. We tend to conclude that disability has an independent effect on the reporting of depression, while medical illness has a negative effect if disability has been controlled for. The last methodological challenge, Bruce mentions, has to do with the way several concepts have been measured. An objective measure obtained from medical records would perhaps have been more reliable. Two sensitivity analyses were performed that demonstrated the robustness of our findings: one for the heterogeneous findings under "other medical condition for which medical attention was received", and one for the risk factor "hypertension".

\section{CONCLUSION}

Disability, especially disability regarding participation, self-care, or social activities is strongly related to late-life depression. The number of somatic diseases does not influence this association. Of note, the relationship between disability and depression has its largest impact among relatively young elderly people (between 60 and 70 years). Clinicians should be aware of this.

\section{ROLE OF FUNDING SOURCE}

This paper reports about the Netherlands Study of Depression among Older patients (NESDO).

The infrastructure for NESDO is funded through the Fonds NutsOhra, (health care insurance) Stichting tot Steun VCVGZ, NAESAD, the Brain and Behaviour Research Fund, and the participating universities and mental health organizations (VU University Medical Center, Leiden University Medical Center, University Medical Center Groningen, Radboud University Nijmegen Medical Center, and GGZinGeest, GGNet, GGZ Nijmegen, GGZ Rivierduinen, Lentis and Parnassia). These organizations are not listed in the (mainly US and UK) list of organizations with whom Elsevier has an agreement about open access policy. We can assure that NESDO data can be published in the open access domain, as has been the case in the past. The funding organizations are not in the position to impose any barriers on the public accessibility of the results.

I have put forward a request for further information on this topic to the help desk EP support but did not get helpful information yet.

\section{CONFLICT OF INTEREST}

None of the authors have disclosed any conflicts of interest or any financial or personal relationships, interests and affiliations relevant to the subject matter of the manuscript.

\section{ACKNOWLEDGMENTS}

The infrastructure for NESDO is funded through the Fonds NutsOhra, Stichting tot Steun VCVGZ, NAESAD, the Brain and Behaviour Research Fund, and the participating universities and mental health organizations (VU University Medical Center, Leiden University Medical Center, University Medical Center Groningen, 
Verhaak, P.F.M., Dekker, J.H., Waal, M.W.M. de, Marwijk, H.W.J. van, Comijs, H.C. Depression, disability and somatic diseases among elderly. Journal of Affective Disorders: 2014, 167(oct.), 187-191

Radboud University Nijmegen Medical Center, and GGZinGeest, GGNet, GGZ Nijmegen, GGZ Rivierduinen, Lentis and Parnassia).

All authors are key members of the research consortium and have made substantial contributions to the conception and design of the study, acquisition of the baseline data, or to writing and commenting the manuscript.

\section{REFERENCES}

American Psychiatric Association, 1994American Psychiatric AssociationDiagnostic and Statistical Manual of Mental Disorders(4th edition)APA, Washington (1994)

Alexopoulos, 2005G.S. AlexopoulosDepression in the elderlyLancet, 365 (2005), pp. 19611970

Barry et al., 2009L.C. Barry, H.G. Allore, M.L. Bruce, T.M. GillLongitudinal association between depressive symptoms and disability burden among older persons

J. Gerontol., 64 (12) (2009), pp. 1325-1332

Bruce, 2001M.L. BruceDepression and disability in late lifeAm. J. Geriatr. sychiatry, 9 (2) (2001), pp. 102-112

Chen et al., 2012C.M. Chen, J. Mullan, Y. Su, D. Griffiths, I. Kreis, H. ChiuThe longitudinal relationship between depressive symptoms and disability for older adults: a population based studyJ. Gerontol., 67 (10) (2012), pp. 1059-1067

Comijs et al., 2011H.C. Comijs, H.W. van Marwijk, R.C. van der Mast, et al.The Netherlands study of depression in older persons (NESDO); a prospective cohort studyBMC Res. Notes, 4 (1) (2011), p. 524

Chwastiak and von Korff, 2003L.A. Chwastiak, M. von KorffDisability in depression and back pain: evaluation of the World Health Organization Disability Assessment Schedule (WHO DAS II) in a primary care settingJ. Clin. Epidemiol., 56 (6) (2003), pp. 507-514

Diefenbach et al., 2012G.J. Diefenbach, D.F. Tolin, C.M. GilliamImpairments in life quality among clients in geriatric home care: associations in depressive and anxiety symptomsint. J. Geriatr. Psychiatry, 27 (8) (2012), pp. 825-835

Diernes, 2006J.K. DjernesPrevalence and predictors of depression in populations of the elderly: a reviewActa Psychiatr. Scand., 113 (2006), pp. 372-387

Dunlop et al., 2004D.D. Dunlop, J.S. Lyons, L.M. Manheim, J. Song, R.W. ChangArthritis and heart disease as risk factors for major depressionMed. Care, 42 (6) (2004), pp. 502511

Evans et al., 2005D.L. Evans, D.S. Charney, R.N. Golden, J.M. Gorman, K.R.R. Krishnan, C.B. NemeroffMood disorders in the medically ill: scientific review and recommendationsBiol. Psychiatry, 58 (2005), pp. 175-189

Garber et al., 2010 C.E. Garber, M.L. Greaney, D. Riebe, C.R. Nigg, P.A. Burbank, P.G. ClarkPhysical and mental health related correlates of physical functioning in community dwelling older adults: a cross sectional studyBMC Geriatr., 10 (2010), p. 6

Kriegsman et al., 1996D.M. Kriegsman, B.W. Penninx, J.T. van Eij, A.J. Boeke, D.J. DeegSelf-reports and general practitioner information on the presence of chronic diseases in community dwelling elderly. A study on the accuracy of patients' self-reports and on determinants of inaccuracyJ. Clin. Epidemiol., 49 (12) (1996), pp. 1407-1417

Licht-Strunk et al., 2009E. Licht-Strunk, H.W.J. van Marwijk, T. Hoekstra, J.W.R. Twisk, M. de. Haan, A.T.F. BeekmanOutcome of depression in later life in primary care: longitudinal cohort study with three years follow-upBMJ Br. Med. J., 338 (2009), p. a3079

Mehta et al., 2008M. Mehta, E. Whyte, E. Lenze, S. Hardy, Y. Roumani, P. Subashan, W. Huang, S. StudenskiDepressive symptoms in late life: associations with apathy, resilience and disability vary between young-old and old-oldInt. J. Geriatr. Psychiatry, 23 (2008), pp. 238-243

Myers and Weissman, 1980J.K. Myers, M.M. WeissmanUse of a self report symptom scale to detect depression in a community sampleAm. J. Psychiatry, 137 (1980), pp. 1081-1084 Nuijen et al., 2006J. Nuijen, F.G. Schellevis, W.A. Satariano, P. Spreeuwenberg, M.D. Birkner, G.A.M. Bos, et al.Comorbidity was associated with neurologic and psychiatric diseases: a general practice-based controlled studyJ. Clin. Epidemiol., 59 (2006), pp. 1274-1284 
Verhaak, P.F.M., Dekker, J.H., Waal, M.W.M. de, Marwijk, H.W.J. van, Comijs, H.C. Depression, disability and somatic diseases among elderly. Journal of Affective Disorders: 2014, 167(oct.) 187-191

Pagan-Rodriguez and Perez, 2013R. Pagan-Rodriguez, S. PerezDepression and selfreported disability among older people in Western EuropeJ. Aging Health, 24 (7) (2013), pp. 1131-1156

Patten et al., 2005S. Patten, C.A. Beck, A. Kassam, J.V.A. Williams, C. Barbui, L.M. MetzLong-term medical conditions and major depression: strenght of associationfor specific conditions in the general populationCan. J. Psychiatry, 50 (4) (2005), pp. 195-202 Penninx et al., 1998BWJH Penninx, J.M. Guralnik, L. Ferruci, E.M. Simonsick, D.J.H. Deeg, R.B. WallaceDepressive symptoms and physical decline in community dwelling older personsJ. Am. Med. Assoc., 279 (1720) (1998), p. 1726

Rush et al., 1996A.J. Rush, C.M. Gullion, M.R. Basco, R.B. Jarrett, M.H. Trivedi

The inventory of depressive symptomatology (IDS): psychometric propertiesPsychol. Med., 26 (3) (1996), pp. 893-897

Russo et al., 2007A. Russo, M. Cesari, G. Onder, V. Zamboni, C. Barillaro, M. Pahor, et al.Depression and physical function: results from the aging and longevity study in the sirente georgraphic area (ilSIRENTE study)J. Geriatr. Psychiatry Neurol., 20 (3) (2007), pp. 131-137

Schillerstrom et al., 2008J.E. Schillerstrom, D.R. Royall, R.F. PalmerDepression, disability and intermediate pathways: a review of longitudinal studies in elders

J. Geriatr. Psychiatry Neurol., 21 (183) (2008), p. 197

Serby and Yu, 2003M. Serby, M. YuOverview: depression in the elderlyMt. Sinai J. Med., 70 (1) (2003), pp. 38-44

Turvey et al., 2009C.L. Turvey, S.K. Schultz, L. Beglinger, D.M. KleinA longitudinal community-based study of chronic illness, cognitive and physical function, and depressionAm. J. Geriatr. Psychiatry, 17 (8) (2009), pp. 632-641

Unutzer, 2007J. UnutzerLate-life depressionN. Engl. J. Med., 357 (22) (2007), pp. 22692276

Vink et al., 2008D. Vink, M.J. Aartsen, R.A. SchoeversRisk factors for anxiety and depression in the elderly: a reviewJ. Affect. Disord., 106 (2008), pp. 29-44

Werff et al., 2010Evd Werff, C.E. Verboom, B.W.J.H. Penninx, W.A. Nolen, J. OrmelExplaining heterogeneity in disability associated with current major depressive disorder: effects of illness characteristics and comorbid mental disordersJ. Affect. Disord., 127 (2010), pp. 203-210

Yanagita et al., 2006M. Yanagita, B. Willcox, K.H. Masaki, R. Chen, Q. He, B. Rodriguez, et al.Disability and depression: investigating a complex relation using physical performance measuresAm. J. Geriatr. Psychiatry, 14 (12) (2006), pp. 1060-1068

\section{TABLES AND FIGURES}


Verhaak, P.F.M., Dekker, J.H., Waal, M.W.M. de, Marwijk, H.W.J. van, Comijs, H.C. Depression, disability and somatic diseases among elderly. Journal of Affective Disorders: 2014, 167(oct.), 187-191

\section{[TABLE 1]}

Characteristics of depressed and non-depressed elderly.

\begin{tabular}{|c|c|c|c|}
\hline & \begin{tabular}{|l|} 
Non-depressed \\
$(N=132)$
\end{tabular} & $\begin{array}{l}\text { Depressed } \\
(N=378)\end{array}$ & Statistical test \\
\hline Gender $(N(\%))$ & & & $\chi^{2}=0.98 ; d f=1$ (n.s.) \\
\hline Male & $51(39 \%)$ & $128(34 \%)$ & \\
\hline Female & $81(61 \%)$ & $250(66 \%)$ & \\
\hline Age (mean) & 70,1 & |70,7 & $\begin{array}{l}t=-0.89 ; d f=508 \\
(\text { n.s. })\end{array}$ \\
\hline Marital status $(N(\%))$ & & & $\begin{array}{l}\chi^{2}=8.73 ; d f=1 ; \\
(p=0.003)\end{array}$ \\
\hline No partner & $46(35 \%)$ & $188(50 \%)$ & \\
\hline Partner & $86(65 \%)$ & $190(50 \%)$ & \\
\hline Educational level & & & $\begin{array}{l}\chi^{2}=24.35 ; d f=2 ; \\
(p<0.001)\end{array}$ \\
\hline Basic & $9(7 \%)$ & $78(21 \%$ & \\
\hline Intermediate & $71(54 \%)$ & $221(58 \%)$ & \\
\hline High & $52(39 \%)$ & $79(21 \%)$ & \\
\hline Income & & & $\begin{array}{l}\chi^{2}=18.47 ; d f=1 \\
(p=0.001)\end{array}$ \\
\hline$<1600 € /$ month & $24(19 \%)$ & $148(41 \%)$ & \\
\hline$>1600 € /$ month & $102(81 \%)$ & $215(59 \%)$ & \\
\hline \multicolumn{4}{|c|}{ Psychopathology past 6 months N (\%) } \\
\hline Only Minor depression & & $13(3 \%)$ & \\
\hline Dysthymia & & $100(26 \%)$ & \\
\hline Single MDD, mild & & $61(16 \%)$ & \\
\hline Single MDD, moderate & & $57(15 \%)$ & \\
\hline Single MDD, severe & & $62(16 \%)$ & \\
\hline Recurrent MDD, mild & & $75(20 \%)$ & \\
\hline $\begin{array}{l}\text { Recurrent MDD, } \\
\text { moderate }\end{array}$ & & $43(11 \%)$ & \\
\hline $\begin{array}{l}\text { Recurrent MDD, } \\
\text { severe }\end{array}$ & & $62(16 \%)$ & \\
\hline \multicolumn{4}{|l|}{ Disability (Mean (sd)) } \\
\hline Total disability score & $6.5(6.7)$ & $25.7(12.4)$ & $\begin{array}{l}t=-16.6 ; d f=490 \\
(p<0.001)\end{array}$ \\
\hline $\begin{array}{l}\begin{array}{l}\text { Understanding and } \\
\text { communicating }\end{array} \\
\end{array}$ & 7.4 (10.9) & $29.0(18.3)$ & $\begin{array}{l}t=-12.7 ; d f=501 \\
(p<0.001)\end{array}$ \\
\hline
\end{tabular}


Verhaak, P.F.M., Dekker, J.H., Waal, M.W.M. de, Marwijk, H.W.J. van, Comijs, H.C. Depression, disability and somatic diseases among elderly. Journal of Affective Disorders: 2014, 167(oct.), 187-191

\begin{tabular}{|c|c|c|c|}
\hline & \begin{tabular}{|l} 
Non-depressed \\
$(N=132)$
\end{tabular} & \begin{tabular}{|l} 
Depressed \\
$(N=378)$
\end{tabular} & Statistical test \\
\hline Getting around & $7.8(13.4)$ & $25.4(22.1)$ & $\begin{array}{l}t=-8.5 ; d f=500 \\
(p<0.001)\end{array}$ \\
\hline Self-Care & $2.3(6.7)$ & $13.5(14.5)$ & $\begin{array}{l}t=-8.5 ; d f=500 \\
(p<0.001)\end{array}$ \\
\hline Social activities & $8.0(9.0)$ & $24.8(14.3)$ & $\begin{array}{l}t=-12.5 ; d f=494 \\
(p<0.001)\end{array}$ \\
\hline Daily life activities & $9.4(14.2)$ & $28.4(20.4)$ & $\begin{array}{l}t=-9.8 ; d f=497 \\
(p<0.001)\end{array}$ \\
\hline Participation in society & $5.6(8.4)$ & $28.4(15.2)$ & $\begin{array}{l}t=-16.2 ; \\
d f=498(p<0.001)\end{array}$ \\
\hline \multicolumn{4}{|l|}{ Somatic diseases } \\
\hline $\begin{array}{l}N \text { of somatic diseases } \\
\text { (mean; sd) }\end{array}$ & $1.23(1.1)$ & $\mid 1.3(1.3)$ & $\begin{array}{l}t=-0.80 ; d f=508 \\
\text { (n.s.) }\end{array}$ \\
\hline Heart disease (\%) & $16 \%$ & $17 \%$ & $t=0.34 ; d f=508$ (n.s.) \\
\hline Diabetes (\%) & $10 \%$ & $12 \%$ & $t=0.66 ; d f=508$ (n.s.) \\
\hline Arthritis (\%) & $14 \%$ & $11 \%$ & $\begin{array}{l}t=-0.77 ; d f=508 \\
(\text { n.s. })\end{array}$ \\
\hline Cancer (\%) & $8 \%$ & $12 \%$ & $t=1.34 ; d f=508$ (n.s.) \\
\hline
\end{tabular}


Verhaak, P.F.M., Dekker, J.H., Waal, M.W.M. de, Marwijk, H.W.J. van, Comijs, H.C. Depression, disability and somatic diseases among elderly. Journal of Affective Disorders: 2014, 167(oct.), 187-191

\section{[TABLE 2]}

Logistic regression on presence of depressive disorder $(N=472)$.

\begin{tabular}{|c|c|c|c|c|c|c|}
\hline \multirow{2}{*}{ Variable } & \multicolumn{2}{|c|}{ Model 1} & \multicolumn{2}{|c|}{ Model 2} & \multicolumn{2}{|c|}{ Model 3} \\
\hline & $\begin{array}{l}\text { Odds } \\
\text { ratio }\end{array}$ & $\begin{array}{l}95 \% \\
\text { conf. } \\
\text { int. }\end{array}$ & $\begin{array}{l}\text { Odds } \\
\text { ratio }\end{array}$ & $\begin{array}{l}95 \% \\
\text { conf. } \\
\text { int. }\end{array}$ & $\begin{array}{l}\text { Odds } \\
\text { ratio }\end{array}$ & $\begin{array}{l}95 \% \\
\text { conf. } \\
\text { int. }\end{array}$ \\
\hline $\begin{array}{l}N \text { of somatic } \\
\text { diseases }\end{array}$ & 1.03 & $\mid \begin{array}{l}0.86- \\
1.23\end{array}$ & $\mid 0.77$ & \begin{tabular}{|l}
$0.59-$ \\
1.00
\end{tabular} & 0.82 & $\begin{array}{l}0.60- \\
1.11\end{array}$ \\
\hline Total disability & & & $\mid 1.23$ & $\begin{array}{l}1.18- \\
1.28 \\
\end{array}$ & 1.27 & $\begin{array}{l}1.20 \\
1.34\end{array}$ \\
\hline Age $70+(60-69=r e f)$ & 1.11 & $\begin{array}{l}0.71- \\
1.72\end{array}$ & $\mid 1.21$ & \begin{tabular}{|l}
$0.67-$ \\
2.19
\end{tabular} & 1.71 & $\begin{array}{l}0.64- \\
4.57\end{array}$ \\
\hline $\begin{array}{l}\text { Partner (no } \\
\text { partner=ref) }\end{array}$ & 0.70 & $\begin{array}{l}0.44- \\
1.14 \\
\end{array}$ & || 0.77 & \begin{tabular}{|l|}
$0.41-$ \\
1.46 \\
\end{tabular} & 0.74 & \begin{tabular}{|l|}
0.39 \\
1.41 \\
\end{tabular} \\
\hline \multicolumn{7}{|l|}{$\begin{array}{l}\text { Educational level } \\
\text { (basic=ref) }\end{array}$} \\
\hline - intermediate & 0.39 & $\begin{array}{l}0.17- \\
0.90\end{array}$ & $\mid 0.48$ & \begin{tabular}{|l|}
$0.16-$ \\
1.44 \\
\end{tabular} & 0.51 & \begin{tabular}{|l|}
$0.17-$ \\
1.56 \\
\end{tabular} \\
\hline - high & 0.22 & $\begin{array}{l}0.09- \\
0.54\end{array}$ & $\mid 0.30$ & $\begin{array}{l}0.09- \\
1.00 \\
\end{array}$ & 0.32 & \begin{tabular}{|l}
0.09 \\
1.06 \\
\end{tabular} \\
\hline Income & 0.47 & $\begin{array}{l}0.26- \\
0.83 \\
\end{array}$ & || 0.95 & $\begin{array}{l}0.43- \\
2.06 \\
\end{array}$ & 0.91 & \begin{tabular}{|l|}
$0.42-$ \\
1.99 \\
\end{tabular} \\
\hline $\begin{array}{l}\text { Interaction: } \\
\text { disability } x \text { age }\end{array}$ & & & & & 0.20 & \begin{tabular}{|l|}
0.05 \\
0.72 \\
\end{tabular} \\
\hline \begin{tabular}{|l|} 
Interaction: somatic \\
disease $x$ age
\end{tabular} & & & & & 0.85 & $\begin{array}{l}0.29- \\
2.50\end{array}$ \\
\hline
\end{tabular}

Statistical significant Odds $(\mathrm{p} \leq 0.05)$ ratios are printed in bold. 
Verhaak, P.F.M., Dekker, J.H., Waal, M.W.M. de, Marwijk, H.W.J. van, Comijs, H.C. Depression, disability and somatic diseases among elderly. Journal of Affective Disorders: 2014, 167(oct.) 187-191

\section{[TABLE 3]}

Logistic regression on the presence of depressive disorder, for 60-70 years old and $70+$ separately.

\begin{tabular}{|c|c|c|c|c|}
\hline \multirow[t]{2}{*}{ Variable } & \multicolumn{2}{|c|}{$\begin{array}{l}\text { 60-69 years } \\
(N=254)\end{array}$} & \multicolumn{2}{|c|}{$70+(N=218)$} \\
\hline & $\begin{array}{l}\text { Odds } \\
\text { ratio }\end{array}$ & $\begin{array}{l}95 \% \text { conf. } \\
\text { int. }\end{array}$ & $\begin{array}{l}\text { Odds } \\
\text { ratio }\end{array}$ & $\begin{array}{l}95 \% \text { conf. } \\
\text { int. }\end{array}$ \\
\hline Total disability & 1.28 & $1.20-1.37$ & 1.19 & $1.13-1.26$ \\
\hline Partner (no partner=ref) & 0.38 & $0.14-1.07$ & 1.26 & $0.54-2.94$ \\
\hline $\begin{array}{l}\text { Educational level }(\text { basic }=r e f) \text { - } \\
\text { intermediate }\end{array}$ & 0.62 & $0.09-4.29$ & 0.31 & ||0.07-1.34 \\
\hline - high & 0.27 & $0.04-2.04$ & 0.22 & $0.04-1.10$ \\
\hline Income & 0.63 & $0.20-2.00$ & 1.88 & $0.60-5.88$ \\
\hline$N$ of somatic diseases & 0.73 & $0.46-1.15$ & 0.86 & $0.61-1.20$ \\
\hline
\end{tabular}

Statistical significant Odds ratios are printed in bold. 
Verhaak, P.F.M., Dekker, J.H., Waal, M.W.M. de, Marwijk, H.W.J. van, Comijs, H.C. Depression, disability and somatic diseases among elderly. Journal of Affective Disorders: 2014, 167(oct.), 187-191

\section{[TABLE 4]}

Final model of logistic regression on the presence of depressive disorder with six successive disability subscales.

\begin{tabular}{|c|c|c|c|c|c|c|c|c|c|c|c|c|}
\hline & \multicolumn{2}{|c|}{$\mid \begin{array}{l}\text { Model } \\
\text { disability } \\
\text { scale 1 }\end{array}$} & \multicolumn{2}{|c|}{$\begin{array}{l}\text { Model } \\
\text { disability } \\
\text { scale } 2\end{array}$} & \multicolumn{2}{|c|}{$\begin{array}{l}\text { Model } \\
\text { disability } \\
\text { scale } 3\end{array}$} & \multicolumn{2}{|c|}{\begin{tabular}{|l} 
Model \\
disability \\
scale 4
\end{tabular}} & \multicolumn{2}{|c|}{\begin{tabular}{|l} 
Model \\
disability \\
scale 5
\end{tabular}} & \multicolumn{2}{|c|}{$\begin{array}{l}\text { Model } \\
\text { disability } \\
\text { scale } 6\end{array}$} \\
\hline & \begin{tabular}{|l||} 
Odd \\
S \\
rati \\
o \\
\end{tabular} & \begin{tabular}{|l|}
95 \\
$\%$ \\
conf \\
\\
\end{tabular} & \begin{tabular}{|l|} 
Odd \\
S \\
rati \\
o
\end{tabular} & \begin{tabular}{|l}
95 \\
$\%$ \\
conf \\
\end{tabular} & \begin{tabular}{|l} 
Odd \\
s \\
rati \\
o
\end{tabular} & \begin{tabular}{|l|}
95 \\
$\%$ \\
conf
\end{tabular} & $\begin{array}{l}\text { Odd } \\
\text { s } \\
\text { rati } \\
\text { o } \\
\end{array}$ & \begin{tabular}{|l|}
95 \\
$\%$ \\
conf \\
\\
\end{tabular} & \begin{tabular}{|l|} 
Odd \\
S \\
rati \\
o \\
\end{tabular} & $\begin{array}{l}95 \\
\% \\
\text { conf } \\
\end{array}$ & \begin{tabular}{|l} 
Odd \\
s \\
rati \\
0 \\
\end{tabular} & $\begin{array}{l}95 \\
\% \\
\text { conf } \\
\end{array}$ \\
\hline $\begin{array}{l}\text { Underst/co } \\
m .\end{array}$ & 1.11 & \begin{tabular}{|l|}
1.08 \\
\\
1.13 \\
\end{tabular} & & & & & & & & & & \\
\hline $\begin{array}{l}\text { Getting } \\
\text { around }\end{array}$ & & & 1.05 & \begin{tabular}{|l}
1.04 \\
- \\
1.07 \\
\end{tabular} & & & & & & & & \\
\hline Self-care & & & & & $\mid 1.14$ & \begin{tabular}{|l|}
1.10 \\
- \\
1.19 \\
\end{tabular} & & & & & & \\
\hline $\begin{array}{l}\text { Social } \\
\text { activities }\end{array}$ & & & & & & & 1.12 & $\begin{array}{l}1.10 \\
- \\
1.15 \\
\end{array}$ & & & & \\
\hline $\begin{array}{l}\text { Daily life } \\
\text { act. }\end{array}$ & & & & & & & & & 1.06 & $\begin{array}{l}1.04 \\
- \\
1.07 \\
\end{array}$ & & \\
\hline $\begin{array}{l}\text { Participati } \\
\text { on }\end{array}$ & & & & & & & & & & & $\mid 1.17$ & $\begin{array}{l}1.14 \\
- \\
1.21 \\
\end{array}$ \\
\hline Partner ${ }^{\text {b }}$ & & & & & & & 0.50 & \begin{tabular}{|l|}
0.30 \\
\\
0.83 \\
\end{tabular} & & & & \\
\hline $\begin{array}{l}\text { Educ. level } \\
\text { intermedia } \\
\text { te. }^{c}\end{array}$ & & & 0.49 & $\begin{array}{l}0.22 \\
- \\
1.11 \\
\end{array}$ & | 0.38 & \begin{tabular}{|l|}
0.17 \\
\\
0.86 \\
\end{tabular} & 0.28 & \begin{tabular}{|l|}
0.11 \\
- \\
0.71 \\
\end{tabular} & 0.43 & \begin{tabular}{|l}
0.19 \\
- \\
0.97 \\
\end{tabular} & 0.40 & $\begin{array}{l}\mathbf{0 . 1 6} \\
- \\
1.04 \\
\end{array}$ \\
\hline \begin{tabular}{|l} 
Educ. \\
level: high \\
c
\end{tabular} & & & 0.30 & $\mid \begin{array}{l}0.13 \\
- \\
0.71\end{array}$ & 0.22 & $\begin{array}{l}0.09 \\
- \\
0.51 \\
\end{array}$ & 0.12 & $\begin{array}{l}0.05 \\
- \\
0.31 \\
\end{array}$ & 0.22 & $\mid \begin{array}{l}0.09 \\
- \\
0.53\end{array}$ & 0.23 & $\begin{array}{l}0.08 \\
- \\
0.64\end{array}$ \\
\hline
\end{tabular}

a

statistical significant odds ratios are printed in bold;

b

no partner=ref;

C

low education=ref. 